\title{
Multifocal Necrotizing Leukoencephalopathy Mimicking Sporadic Creutzfeldt-Jakob Disease
}

\author{
Daniele Imperiale $^{\mathrm{a}}$ Stefano Taraglio ${ }^{\mathrm{b}}$ Cristiana Atzori ${ }^{\mathrm{a}}$ Roberto Testi ${ }^{\mathrm{c}}$ Carlo Buffa ${ }^{\mathrm{a}}$ \\ Antonio Mighelia \\ ${ }^{a}$ Neurology Unit, ${ }^{b}$ Pathology Unit and ' Forensic Medicine Unit, Centro Malattie da Prioni DOMP, ASL3, Torino, Italy
}

\section{Dear Sir,}

Creutzfeldt-Jakob disease (CJD) is a prion encephalopathy characterized by rapidly progressive dementia, myoclonus and various neurological symptoms. The diagnosis is supported by a typical EEG pattern with periodic spike-wave complexes (PSWC) and/or a positive CSF 14-33 protein test [1]. Additionally, raised CSF tau levels $(>1,300 \mathrm{pg} / \mathrm{ml})$ and certain MRI aspects - i.e. high diffusion-weighted imaging (DWI) and fluid-attenuated inversion recovery signals involving deep nuclei and the cerebral cortex - have been shown to be useful in the diagnostic work-up of prion diseases [2, 3].

Multifocal necrotizing leukoencephalopathy (MNL) is an uncommon clinicopathological entity usually diagnosed in immune-suppressed patients and characterized by multiple foci of vacuolation at the basis pontis and, less frequently, at the supratentorial level [4].

Here we describe an MNL patient mimicking sporadic CJD in its whole clinical, EEG, MRI and CSF aspects.

\section{Case Report}

In July 2005, a 64-year-old woman with chronic respiratory failure was referred to our intensive-care unit because of severe hyponatremia $(110 \mathrm{mEq} / \mathrm{l})$ and recurrent generalized tonic-clonic seizures. Progressive ideomotor delay, visual and gait difficulties were reported in the previous weeks. Neurological examination evi- denced a decerebrate coma with preserved brainstem reflexes. Diffuse PSWC were evident upon EEG recording (fig. 1). In spite of sodium correction, valproate administration and supportive therapy, no clinical or EEG improvement was observed. The CSF 14-3-3 protein test was positive, and tau concentration was raised (5,080 pg/ml). Brain MRI showed mildly high DWI signals involving the left parietal cortex (not shown). PRNP gene analysis disclosed a $129 \mathrm{VV}$ genotype with no mutations. A diagnosis of clinically probable sporadic CJD was made. Tau concentration had risen to $10,480 \mathrm{pg} / \mathrm{ml}$ when a second CSF sample was drawn 4 weeks later. The patient died after 2 months from multiple organ failure.

Because of suspected CJD, postmortem analysis was limited to the intracranial content. On eosin-hematoxylinstained sections, typical lesions of prion diseases (spongiosis, gliosis, and neuron loss) were absent. Furthermore, Western blot and immunohistochemistry studies failed to detect the pathologic prion protein. Therefore, a CJD diagnosis was ruled out.

Instead, disseminated foci of vacuolation were evident in the transverse tracts of the basis pontis and were associated with scattered axonal swellings and activated macrophages (fig. 2). Rare foci of vacuolation were present also at the supratentorial level (not shown). A pathological diagnosis of MNL was made.

\section{Discussion}

To the best of our knowledge, this is the first report of an MNL case imitating sporadic CJD in its whole clinical, EEG, MRI and CSF aspects. The CJD diagnosis was initially suggested by the clinical history, the EEG picture and the lack of improvement in spite of sodium correction and valproate administration.

Regarding the EEG data, PSWC are present in about two thirds of CJD patients [5]. They have also recently been reported in an MNL case [6]. PSWC are presumably related to cortical disconnection from deep generators, as in diffuse axonal injury [7].

Interestingly, the MRI picture of our patient paralleled certain aspects of prion diseases (i.e. high signals involving the cortical ribbon on DWI scans) [3].

The suspected CJD was greatly supported by the CSF data (positive 14-3-3 protein test and very raised tau levels) [1]. In particular, tau concentration was 5,080 $\mathrm{pg} / \mathrm{ml}$ in the first examination and 10,480 $\mathrm{pg} / \mathrm{ml}$ in the second one (4 weeks later). Notably, similar tau levels have been reported only in prion diseases and severe brain trauma $[3,8]$. This CSF picture was presumably related to axonal injury, as confirmed by neurofilament immunostaining of axonal swellings.

The pathogenesis of MNL in our patient is not clear. MNL usually affects immunesuppressed subjects, but rare immunecompetent patients have been described. On a clinical basis, the main differential di-

\section{KARGER}

Fax +4161306 1234 E-Mail karger@karger.ch www.karger.com
Daniele Imperiale, MD

Neurology Unit and Centro Malattie da Prioni DOMP - ASL3

Via Cibrario 72

IT-10144 Torino (Italy)

Tel. +39 011439 3296, Fax +39 011439 3503, E-Mail imperiale@asl3.to.it 


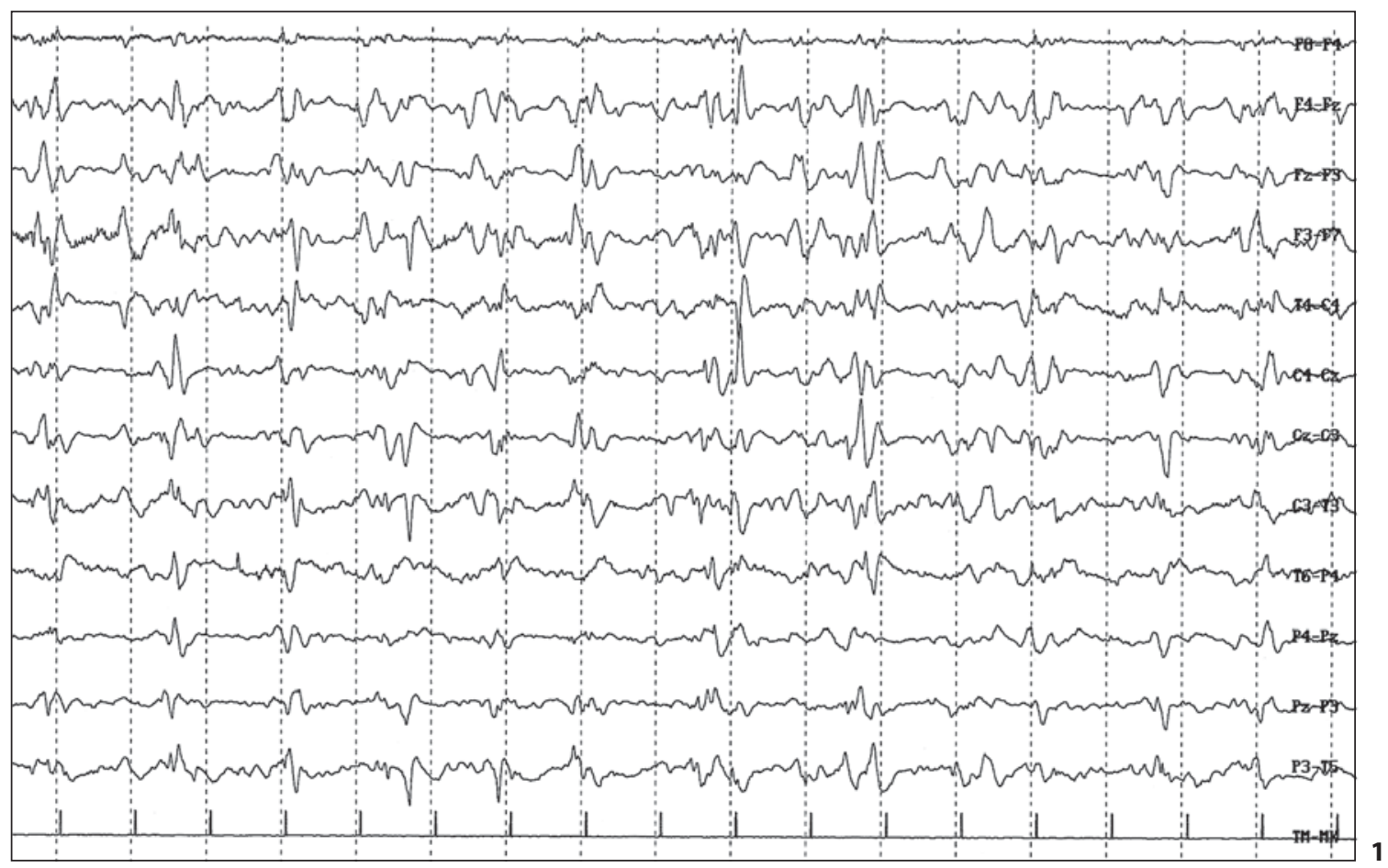

Fig. 1. EEG at admission demonstrating persistent PSWC over all the scalp electrodes.

Fig. 2. A Hematoxylin-eosin-stained section of the basis pontis demonstrating microscopic foci of vacuolation involving the transverse tracts. B Myelin vacuolation on Luxol fast blue stain. C Neurofilament immunostaining of the basis pontis demonstrating scattered axonal swellings and spheroids. D CD68 immunostaining highlighting scattered macrophages infiltrating white matter tracts.
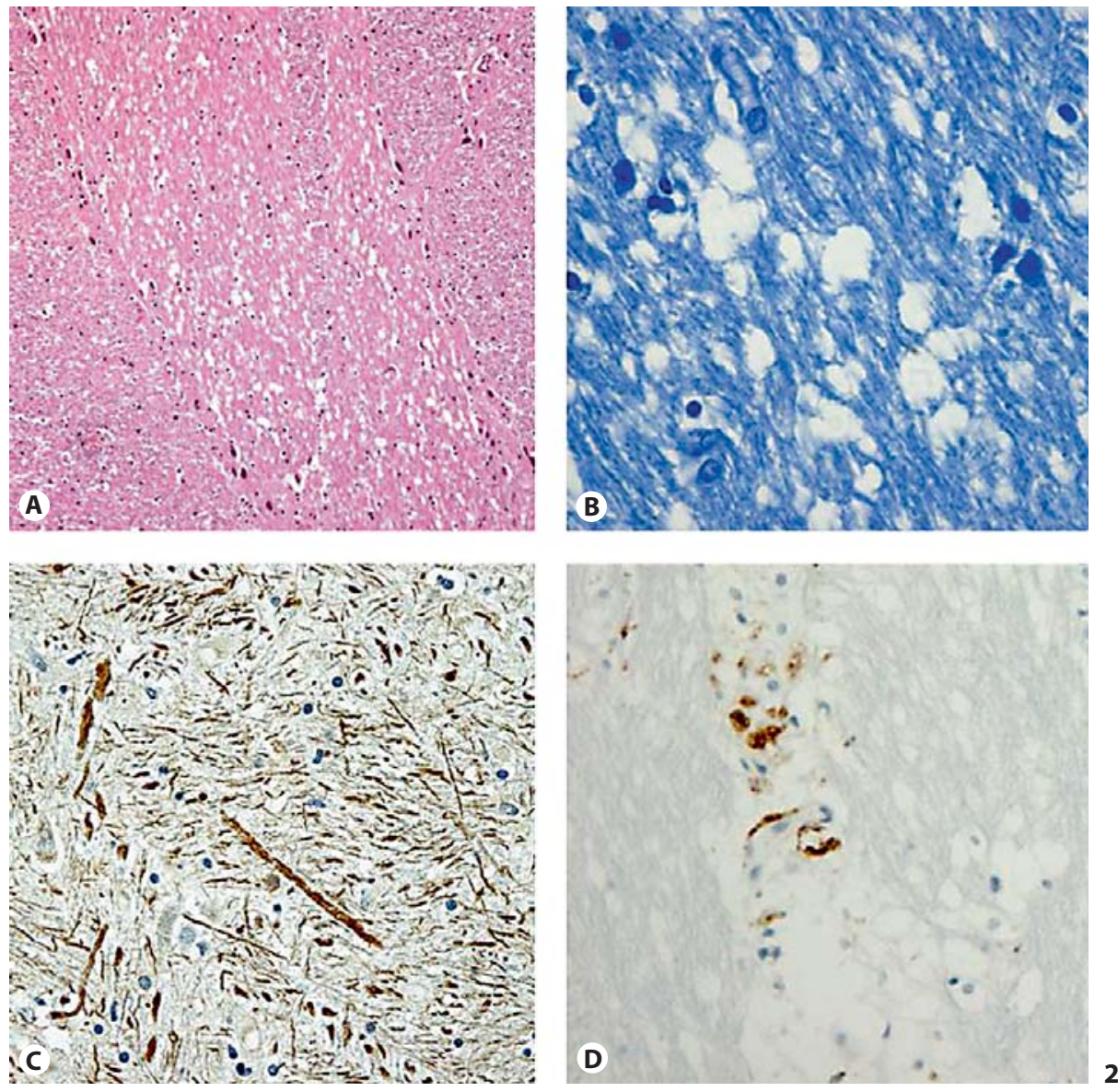
agnosis of MNL is central pontine myelinolysis. Axonal damage has been pathologically proven in both conditions $[9,10]$. The histological aspects of MNL and central pontine myelinolysis could represent different gradations of the same pathological process. The correlation between sodium levels and central pontine myelinolysis is largely accepted. Plasma sodium variations have been reported in MNL patients, too. In our MNL case, the very low sodium concentration at onset could be relevant to the initiation of MNL lesions.

In conclusion, MNL should be considered in cases of a critically ill patient with clinical, EEG and CSF findings suggestive of CJD.

\section{Acknowledgements}

The authors thank Maria Grazia Debandi, Monica Attuoni and Daniela Dolce for helpful technical assistance. The Centro Malattie da Prioni DOMP is supported by Regione Piemonte - Ricerca Sanitaria Finalizzata.

\section{References}

1 WHO: WHO manual for surveillance of human transmissible spongiform encephalopathies including variant Creutzfeldt-Jakob disease. Geneva, WHO, 2003.

- Otto M, Wiltfang J, Cepek L, Neumann M, Mollenhauer B, Steinacker P, Ciesielczyk B, Schulz-Schaeffer W, Kretzschmar HA, Poser S: Tau protein and 14-3-3 protein in the differential diagnosis of Creutzfeldt-Jakob disease. Neurology 2002;58:192-197.

-3 Kallenberg K, Schulz-Schaeffer WJ, Jastrow U, Poser S, Meissner B, Tschampa HJ, Zerr I, Knauth M: Creutzfeldt-Jakob disease: comparative analysis of MR imaging sequences. AJNR Am J Neuroradiol 2006;27:14591462.

-4 Anders KH, Becker PS, Holden JK, Sharer LR, Cornford ME, Hansen LA, Hamilton R, Vinters HV: Multifocal necrotizing leukoencephalopathy with pontine predilection in immunosuppressed patients: a clinicopathologic review of 16 cases. Hum Pathol 1993;24: 897-904.

5 Steinhoff BJ, Zerr I, Glatting M, SchulzSchaffer W, Poser S, Kretzschmar HA: Diagnostic value of periodic complexes in Creutzfeldt-Jakob disease. Ann Neurol 2004; 56:702-708.
6 Fernandez-Torre JL, Arce F, Martinez-Martinez M, Gonzalez-Rato J, Infante J, Calleja J: Necrotizing leukoencephalopathy associated with nonconvulsive status epilepticus and periodic short-interval diffuse discharges: a clinicopathological study. Clin EEG Neurosci 2006;37:50-53.

7 Neidermeyer E: EEG and dementia; in Neidermeyer E, Lopes da Silva F (eds): Electroencephalography: Basic Principles, Clinical Applications and Related Fields, ed 4. Baltimore, Lippincott, Williams \& Wilkins, 1999, p 251.

8 Ost M, Nylen K, Csajbok L, Olsson Ohrfelt A, Tullberg M, Wikkelso C, Nellgard P, Rosengren L, Blennow K, Nellgard B: Initial CSF total tau correlates with 1-year outcome in patients with traumatic brain injury. Neurology 2006;67:1600-1604.

9 Medana IM, Esiri MM: Axonal damage: a key predictor of outcome in human CNS diseases. Brain 2003;126:515-530.

10 Sharshar T, Gray F, Poron F, Raphael JC, Gajdos P, Annane D: Multifocal necrotizing leukoencephalopathy in septic shock. Crit Care Med 2002;30:2371-2375. 